\title{
UMA ANÁLISE MULTIDIMENSIONAL DA PRÁTICA DO PROSELITISMO NO ENSINO RELIGIOSO FRENTE AO ART. 33 DA LDB
}

A MULTIDIMENSIONAL ANALYSIS OF THE PRACTICE OF PROSELITISM IN RELIGIOUS EDUCATION IN FRONT OF ART. 33 OF THE LDB Gustavo Leite Castello Branco ${ }^{84}$

\footnotetext{
${ }^{84}$ Graduado em Direito pela UFPB, Especialista em Direito Empresarial e Advocacia Empresarial (2014) pela Universidade Anhanguera-Uniderp, Mestre em Teologia com concentração em História da Igreja (2007) pela Trinity School for Ministry (USA - PA), Mestre em Ciências das Religiões pela UFPB. Email: profgustavocastello@gmail.com
} 


\section{RESUMO}

No presente trabalho, apresentamos a questão do proselitismo como um fenômeno intrínseco às religiões em geral e como elemento integrante da própria espiritualidade dos chamados "monoteísmos históricos". A partir do Art. 33 da LDB, empreendemos uma análise multifocal da vedação de proselitismo no Ensino Religioso ministrado em instituições públicas. Nessa análise contemplamos as dimensões pedagógica, jurídica, teológica e epistemológica. Ao final, com base na análise feita, sugere-se algumas diretrizes em torno da postura a ser tomada no trato da questão do proselitismo dentro do Ensino Religioso. O tipo de pesquisa utilizado foi pura, com abordagem qualitativa, fazendo uso da técnica de revisão bibliográfica.

\section{PALAVRAS-CHAVE}

Proselitismo, Tolerância, Estado Laico, Ensino Religioso.

\section{ABSTRACT}

In this work we present the issue of proselitism as being part of religion as a whole and a constituent element of the spirituality of the so called historical monotheisms. Beginning with Article 33 of LDB we undertake a multifocal analysis of the prohibition of proselitism in the context of religious education in public schools. In this analysis we considered the pedagogical, legal, theological, and epistemological aspects. In the end, the article points to some guidelines regarding how one should deal with the proselitism issue in the context of Religious Education. The type of research used was pure, with a qualitative approach, making use of the bibliographic review technique.

\section{KEYWORDS}

Proselytism, Tolerance, Lay State, Religious Education.

\section{INTRODUÇÃO}

A Lei de Diretrizes e Bases da Educação Nacional (BRASIL, Lei 9.394, 1996), em seu Artigo 33, ao incluir o Ensino Religioso (ER) como "parte integrante da formação básica do cidadão" e como "disciplina dos horários normais das escolas públicas de ensino 
fundamental" reconhece a religiosidade como manifestação humana e social presente nas diversas culturas desde tempos imemoriais, reinserindo o fenômeno religioso no rol dos fatos sociais dignos de serem estudados a partir de uma disciplina própria.

Ao operar tal inserção, entretanto, o legislador teve o cuidado de destacar que o ER não poderia ter fins "proselitistas", ou seja, de captação de fiéis para uma tradição religiosa em particular. Tal ressalva, expressa no referido dispositivo legal através das palavras "vedadas quaisquer formas de proselitismo", veio no sentido de resguardar a laicidade do Estado e garantir que a máquina pública não fosse utilizada para favorecer qualquer credo em detrimento de outros, o que, em tese, feriria o art. 19, I da Constituição Federal (BRASIL, 1988) que afirma:

Art.19. É vedado à União, aos Estados, ao Distrito Federal e aos Municípios:

I - Estabelecer cultos religiosos ou igrejas, subvencioná-los, embaraçar-lhes o funcionamento ou manter com eles ou seus representantes relações de dependência ou aliança, ressalvada, na forma da lei, a colaboração de interesse público.

Ocorre que, como esclareceremos no presente trabalho, o chamado "proselitismo religioso" é parte integrante e essencial do fenômeno religioso, sendo praticado, em maior ou menor grau de intensidade, pelas diversas tradições religiosas que a humanidade tem produzido. Mais do que isso, o "fazer proselitismo" decorre diretamente do impulso humano de se expressar, de conhecer e de se fazer conhecido.

\section{PROSELITISMO RELIGIOSO: UMA PERSPECTIVA PEDAGÓGICA}

É certo que a indiferença não é o melhor remédio para lidar com as diferenças. Em outras palavras, não se resolvem conflitos e divergências fingindo que eles não existem, nem mesmo pela imposição de uma "harmonização" externa e forçada. $\mathrm{Na}$ tentativa de evitarem o confronto de ideias, perspectivas e 
sentimentos, muitos acabam deseducando para o diálogo, promovendo uma "alteridade" forçada e consagrando a mediocridade e a estagnação do saber. Isso é especialmente verdade no campo do $\mathrm{ER}$, como esclarece o comentário do professor Eduardo Gross, a respeito da diversidade encontrada na sociedade brasileira e dos objetivos das pesquisas no Campo das Ciências das Religiões e do ER:

Diferentes manifestações religiosas apresentem reivindicações de verdade distintas e muitas vezes conflitantes, e diante disso não é possível se manter representações idealizadas da religião extremamente simplórias, de sentido harmonizante. "Todas as religiões levam a Deus", "a religião dá sentido à vida", "todas as religiões são boas" são manifestações otimistas de boa vontade e talvez até de respeito às diferenças, entretanto elas não podem ser consideradas expressões suficientes para estabelecer o objetivo da pesquisa sobre a religião e nem do Ensino Religioso. Para isso, é preciso não camuflar as distinções de proposição de sentido que se encontram nas diferentes tradições religiosas. Só assim também se pode de fato compreender e também visar a superação de conflitos religiosos. (GROSS, 2014, p. 132)

Com base nesse entendimento é que se acredita que propostas de ensino que pretendam promover uma pretensa atitude de "tolerância" em detrimento da liberdade de proselitismo estão fadadas ao fracasso e correm o grande risco de promoverem mais intolerância religiosa, ou seja, de obterem como produto final aquilo que pretendiam a todo custo desencorajar.

Há muito que o antigo modelo de educação como um mero processo de transferência de informações do docente (visto como "aquele que sabe") para o discente (visto como "aquele que nada sabe") encontra-se superado. Uma das figuras que, no contexto brasileiro, muito contribuiu para a superação de tal paradigma pedagógico foi Paulo Freire, que comentando sobre a formação de professores, afirmou: 
É preciso, sobretudo, e aíjá vai um destes saberes indispensáveis, que o formando, desde o princípio mesmo de sua experiência formadora, assumindo-se como sujeito também da produção do saber, se convença definitivamente de que ensinar não é transferir conhecimento, mas criar as possibilidades para a sua produção ou a sua construção.(FREIRE, 1996, p. 12)

No entendimento deste mestre, a tarefa de ensinar (em que necessariamente encontra-se embutida o Ensino Religioso) não se exaure com uma mera transferência de conteúdos onde o educando é visto como um mero objeto, mas implica na tarefa de ensinar a aprender e a pensar criticamente. Assim (FREIRE, 1996, p.13) "quanto mais criticamente se exerça a capacidade de aprender tanto mais se constrói e desenvolve o que venho chamando 'curiosidade epistemológica', sem a qual não alcançamos o conhecimento cabal do objeto." Por outro lado, no processo de aprendizado, de modo nenhum se deve subestimar os saberes que os educandos já possuem e trazem para a sala de aula:

Por isso mesmo pensar certo coloca ao professor ou, mais amplamente, à escola, o dever de não só respeitar os saberes com que os educandos [...] chegam a ela - saberes socialmente construídos na prática comunitária - mas também, [...] discutir com os alunos a razão de ser de alguns desses saberes em relação com o ensino dos conteúdos. (FREIRE, 1996, p. 15)

Dentre os saberes que os educandos trazem para uma sala de aula de ER estão as razões pelas quais entendem ser necessário a partilha de sua fé com outros, isto é, o "fazer proselitismo", bem como as razões pelas quais entendem que aquela fé (e não outra) corresponde à melhor ou à única explicação verdadeira sobre o mundo ao seu redor. Sendo assim, ideias simplistas e dogmáticas do tipo "precisamos combater toda forma de proselitismo e intolerância religiosa", quando assumidas e defendidas a priori pelo educador tendem a empobrecer o ensino e favorecer uma postura de silencio consentido frente a convicções reprimidas. 
Afinal, não se educa calando a boca, mas estimulando a participação cidadã e a capacidade de expressão, ao mesmo tempo, discordante e respeitosa.

\section{PROSELITISMO RELIGIOSO:UMA PERSPECTIVAJURÍDICA}

A Constituição da República Federativa do Brasil, nos incisos IV e VI do Art. $5^{\circ}$, garante a Liberdade de Manifestação do Pensamento e a Liberdade de Consciência e Crença como Direitos Fundamentais, portanto, como cláusulas pétreas do sistema jurídico brasileiro ${ }^{85}$. Marcelo Novelino, ao tratar sobre os fundamentos para a proteção do direito de Liberdade de Manifestação do Pensamento, reconhece:

O homem não se contenta apenas em ter suas próprias opiniões. Ele quer expressá-las, convencer os outros de suas idéias. As convicções íntimas podem existir independente do Direito, mas a liberdade para exteriorizar idéias e opiniões pessoais necessita de proteção jurídica. (NOVELINO, 2013, p. 474)

Por sua vez, Celso Ribeiro Bastos e Ives Gandra Martins (1989, p.40) são diretos, ao afirmar: "É da sua natureza [do ser humano] o ir mais longe: o procurar convencer os outros; o fazer proselitismo" e, em virtude disso, ele precisa "antes de mais nada saber do que não será apenado em função de suas crenças e opiniões."

Na mesma linha de raciocínio, os juristas Lelio Maximino Lellis e Carlos Alexandre Hees, em seu Manual de Liberdade Religiosa, tratam da relação entre proselitismo religioso e invasão de privacidade, o que pode muito bem ser tomado como paradigma para um tratamento da relação entre proselitismo e intolerância:

Sem dúvida, o proselitismo religioso é um conceito controverso e, infelizmente, mal-

\footnotetext{
${ }^{85}$ Clausula Pétrea são direitos (ou garantias constitucionais) que, por força do Art. $60, \S 4^{\circ}$ da CF não podem ser revogadas nem mesmo por emenda constitucional.
} 
empregado quando confundido prima facie com invasão de privacidade alheia [...] O caráter proselitista está inserido na própria essência humana. O ser humano não se contenta com o simples fato de pensar, ou simplesmente expressar suas opiniões. (LELLIS; HEES, 1989, p. 40)

Como se percebe, todos esses juristas reconhecem a prática do proselitismo, não como um comportamento necessariamente reprovável, mas como um desdobramento natural da condição humana, e mesmo algo a ser protegido. Talvez, por isso mesmo, a Declaração Universal dos Direitos Humanos (2016), da qual o Brasil é signatário, em seu Art. XVIII, tenha estabelecido que:

Todo ser humano tem direito à liberdade de pensamento, consciência e religião; este direito inclui a liberdade de mudar de religião ou crença e a liberdade de manifestar essa religião ou crença, pelo ensino, pela prática, pelo culto e pela observância, em público ou em particular.

Interessante observar que este dispositivo legal evidencia que no direito à liberdade de consciência e religião encontra-se implícita a garantia do direito de ser convencido ("liberdade de mudar de religião ou crença") e o direito de convencer ("liberdade de manifestar essa religião ou crença"). Em outras palavras, na clara compreensão da Declaração Universal dos Direitos Humanos sobre esse assunto, a salvaguarda do direito fundamental de liberdade de expressão (manifestação) do pensamento e de crença implica necessariamente na salvaguarda do direito ao "proselitismo".

Portanto, como se pode ver, a vedação ao proselitismo contida no artigo 33 da LDB precisa ser corretamente interpretada, sob pena de poder ser reprovada em eventual controle de constitucionalidade e / ou controle de convencionalidade ${ }^{86}$. Em

${ }^{86}$ Os Controles de constitucionalidade e de convencionalidade representam uma análise feita de uma norma jurídica para saber se a mesma contraria a Constituição Federal (no 
outras palavras, tal vedação não deve ser interpretada como uma espécie de orientação pedagógica para que docentes desencorajem discentes a expressar publicamente a sua fé no intuito de convencer outros, mas sim como uma prescrição de cunho ético, dirigida a todo o sistema de ensino, no sentido de evitar que a sala de aula de ER nas escolas públicas se torne a expressão de uma única tradição religiosa.

\section{PROSELITISMO RELIGIOSO:UMA PERSPECTIVA TEOLÓGICA}

No contexto das sociedades secularizadas ocidentais, a identificação entre "proselitismo religioso" e "intolerância" é algo bastante difundido, até mesmo nos meios de estudo acadêmico das religiões. À identificação apressada entre essas duas realidades, o teólogo reformado Leslie Newbigin faz uma crítica bastante lúcida, utilizando-se da conhecida e muito citada estória do rei, os cegos e o elefante. No conto, que pretende apresentar uma postura de agnosticismo religioso como ideal, o rei se diverte com seus cortesãos, ao assistir alguns homens cegos tocando em diferentes partes de um elefante e dando, cada um deles, a descrição de um animal diferente. Sobre essa narrativa, Newbigin comenta:

A estória é contada da perspectiva do rei e seus cortesãos, que não são cegos e conseguem ver que os homens cegos são incapazes de alcançar a completa realidade do elefante e só conseguem captar parte da verdade. A estória é constantemente contada para neutralizar as afirmações das grandes religiões, para sugerir que estas aprendam a humildade e reconheçam que nenhuma delas pode alcançar mais do que um aspecto da verdade. Mas, é claro, a verdadeira moral da estória é exatamente o oposto. Se o rei também fosse cego não haveria estória. A estória é contada pelo rei e representa a reivindicação imensamente arrogante de alguém que enxerga a verdade completa, a qual todas as religiões

caso do Controle de Constitucionalidade) ou um tratado ou convenção internacional (no caso do Controle de Convencionalidade). 
mundiais continuam apenas a buscar, tateando.

(NEWBIGIN, 1989, p. 9-10)

Como afirmou Newbigin (1989, p. 21-22) o fato de nosso conhecimento ser limitado "não deve ser usado para desqualificar a própria afirmação de se conhecer algo", afinal, "como alguém pode saber que a realidade última é maior do que qualquer afirmação possível sobre ela?" Assim, quando o pluralismo deixa de ser um fato social acolhido como positivo e passa a ser ideologizado, a militância em favor deste pode facilmente se tornar tão excludente quanto qualquer outra postura totalitária.

Fato é que a imagem negativa atribuída à prática do proselitismo religioso no Brasil contemporâneo se deve, em grande parte, às atrocidades cometidas em nome de "Deus" durante o processo de colonização, através de uma verdadeira imposição cultural recheada de "conversões" forçadas, bem como às atuais expressões de intolerância e violência religiosas no âmbito nacional e internacional; dentre essas, a ameaça do terrorismo religioso.

Entretanto, em nome da verdade, da tolerância, e do contínuo processo de diálogo construtivo entre os diferentes, devemos insistir na necessária diferenciação entre proselitismo religioso e intolerância religiosa, pois um não implica necessariamente no outro.

Acreditamos que todas as tradições religiosas, quer sejam monoteístas, politeístas, panteístas, deístas ou ateístas devam encontrar dentro de seu próprio ethos fundamentos para o respeito às diferenças, sem a necessidade de ter que se valer de princípios secularistas para tanto. Ademais, acreditamos ser esta a melhor maneira de se lidar com a questão do proselitismo em sala de aula, isto é, levando cada educando a descobrir, dentro de sua própria confissão de fé, razões e justificativas para permitir a discordância e a convivência com os que pensam diferente.

Um exemplo que demonstra a possibilidade de tal empreendimento, até mesmo em uma tradição que afirme, creia e propague a existência em um Deus único, considerando todos os outros, falsos deuses a serem abandonados, é o comentário feito por Newbigin sobre a postura cristã frente à sua própria 
reivindicação de verdade, deixando claro que compreender-se como "testemunha" da verdade, ainda que absoluta, não é o mesmo que compreender-se como detentor (possuidor) de toda essa verdade:

Existe, na verdade, um espaço para o agnosticismo na vida cristã. Em um sentido específico nós somos - ao lado de outros pessoas que andam em busca da verdade. A tradição apofática [ou "via negativa"] em teologia sempre insistiu que não existe imagem humana ou conceito que possa alcançar a plena realidade de Deus. [...] Quando os cristãos afirmam que Jesus é o caminho, o verdadeiro e vivo caminho pelo qual nós podemos vir ao Pai (Jo.16:4), não estão afirmando saber de tudo. Eles estão dizendo que estão no caminho e estão convidando outros a se juntarem a eles e continuarem em direção à plenitude da verdade, em direção ao dia quando então conheceremos como somos conhecidos. (NEWBIGIN, 1989, p. 12)

Não há a necessidade de se impor uma privatização forçada da fé cristã, fazendo-a ser o que ela não é, para que se promova uma postura de tolerância e respeito á diversidade. Como afirma Von Sinner (2010, p. 329-330):

Parece inteiramente óbvio que o cristianismo tem uma dimensão pública. Em sua resposta diante do sumo sacerdote Anás, Jesus de Nazaré não deixou dúvidas quanto a isto: "Eu falei abertamente [no grego: com franqueza, parrhesia] ao mundo [to kosmo], eu sempre ensinei nas sinagogas e no Templo, onde todos os judeus se reúnem, e nada disse em segredo" (Jo.18:20; Tradução Ecumênica da Bíblia)

Isso significa que é da própria natureza desta tradição a reivindicação de sua mensagem como verdade pública e histórica. Por isso que para um cristão 
(...) seu relacionamento com Deus não pode ser separado daqueles atos pelos quais Deus se revelou e tem cumprido o seu propósito para o mundo [...] a sua vida de devoção a Deus será expressa em e através de seu envolvimento com a história. (NEWBIGIN, 1989, p. 67)

Portanto, dentro desta cosmovisão, o proselitismo religioso faz parte da própria vivência da espiritualidade, e desencorajá-lo seria como insistir com um budista para que não mais praticasse meditação. Assim, para que haja uma maior honestidade em relação à prática do proselitismo religioso por parte dos chamados monoteísmos históricos (com exceção, talvez, do judaísmo), é preciso que haja um reconhecimento de sua própria razão de ser e um respeito à sua natureza. Assim, por exemplo, a mensagem cristã (NEWBIGIN, 1989, p. 6) é anunciada como "a verdade, não como uma possível opinião dentre outras. E é claro que ela pode ser rejeitada, e é rejeitada." Tal postura, no entanto, não implica necessariamente em atitude discriminatória para com pessoas de outros credos, nem muito menos justifica qualquer ato de intolerância religiosa.

Neste ponto, é importante enfatizar que, embora seja comum se dizer que a prática de proselitismo seja uma característica exclusiva dos chamados monoteísmos históricos, fato é que toda afirmação de conhecimento é também, de certa forma, uma afirmação carregada de intenção. Aliás:

A desvalorização das afirmações de crença como meramente subjetivas [...] envolve um absurdo lógico. Ela pressupõe a possibilidade de um conhecimento "objetivo" que não seja conhecimento crido como verdade por alguém. [...] Eu não posso, ao mesmo tempo, dizer: "É nisso que acredito" e "A verdade é algo diferente disso que eu acredito" (NEWBIGIN, 1989, p. 22)

Assim, toda e qualquer afirmação de conhecimento já é, em si mesma, uma afirmação carregada de intencionalidade. Ainda que a natureza dessa intencionalidade possa não ficar clara em todas as ocasiões, a afirmação continuará sendo a publicação de 
uma crença ou descrença em alguma forma de conhecimento, de modo que:

Quando digo "Eu creio" não estou simplesmente descrevendo um sentimento ou uma experiência interior: estou afirmando o que acredito ser verdade, e, portanto, o que é verdade para todo mundo. O teste de meu comprometimento com essa crença ocorrerá quando eu estiver pronto para publicá-la, dividi-la com outros e permitir seu julgamento e - se necessário - correção. (NEWBIGIN, 1989, p. 22)

Portanto, o impulso por se afirmar conhecimentos como verdade pública não é uma característica contingente a algumas tradições religiosas em específico, mas uma maneira humana de ser e de se expressar no mundo. Afinal (NEWBIGIN, 1989, p. 22), “o relativismo que não está disposto a falar de verdade, mas apenas sobre o que é verdade para mim é uma fuga do sério empreendimento de viver." E esse impulso constitui, inclusive, uma das características centrais do pensar científico, como comentaremos a seguir.

\section{PROSELITISMO RELIGIOSO:UMA PERSPECTIVA EPISTEMOLÓGICA}

Ao que pese a existência de uma postura suspeita por parte da academia em relação à prática do proselitismo religioso, esta mesma academia depende totalmente de uma forma de impulso proselitista de professores e pesquisadores para o avanço do conhecimento científico. A produção, transmissão e avanço do conhecimento como um todo estão intimamente ligados à arte de afirmar e sustentar publicamente crenças pessoais como verdades públicas.

Comentando sobre o processo de descobertas científicas, Newbigin (1989, p. 47), chamando a nova descoberta de "um novo e mais atraente paradigma" que é oferecido como "uma visão da realidade a qual recomenda a si mesma por sua beleza, racionalidade e abrangência intrínsecas", acaba expondo de maneira clara a questão que estamos explicando: 
A aceitação de tal visão é um ato pessoal, um ato de julgamento pessoal ao qual a pessoa se compromete, sabendo que outros podem discordar e até provar que ela está errada. Essa aceitação envolve um comprometimento pessoal, mas nem por isso consiste em uma questão meramente subjetiva. O cientista que se compromete com a nova visão o faz [...] com intenção universal. Ele acredita que ela seja objetivamente verdadeira, e, portanto, ele faz com que ela seja amplamente divulgada, propõe discussões e procura persuadir seus colegas cientistas de que tal visão representa um relato verdadeiro da realidade [...] É à sua crença pessoal que ele se compromete e sobre a qual ele arrisca a sua reputação científica. Entretanto, em nenhum momento essa crença é apresentada como sua mera opinião subjetiva. É sustentada com "intenção universal", como sendo um verdadeiro relato da realidade, o qual todas as pessoas devem aceitar e o qual se provará verdadeiro tanto por verificação experimental como pelo fato de abrir caminho para novas descobertas. É oferecido não como uma opinião privada, mas como verdade pública. (NEWBIGIN, 1989, p. 47)

Isso nos aponta para a própria natureza daquilo que chamamos de conhecimento. Não há espaço neste trabalho para uma discussão epistemológica aprofundada, entretanto, uma breve crítica à epistemologia contemporânea ocidental, a partir da perspectiva do filósofo Michael Polanyi ${ }^{87}$, mostra-se bastante útil para, por um lado resgatarmos o papel fundamental desempenhado por uma atitude proselitista na transmissão e avanço do conhecimento humano, e por outro, estabelecermos a

\footnotetext{
${ }^{87}$ Tendo vivido entre 1891-1976 Polanyi foi um polímata húngaro-britânico que fez contribuições teóricas importantes para a físico-química, economia e filosofia. Nesta última área sua grande contribuição deu-se no campo da epistemologia, através de sua teoria do conhecimento como "Conhecimento Pessoal".
} 
diferença entre a atitude de se afirmar verdades com intento universal e atitudes de intolerância.

Para Polanyi existe um grande erro em se enxergar a verdade como uma realidade exterior e objetiva esperando por ser descoberta. Nisto encontra-se aparentemente alinhado com a epistemologia de filósofos pós-cartesianos como David Hume, Friederich Nietzsche e Kant, que criticaram e mesmo negaram a possibilidade da objetividade absoluta ou mesmo de qualquer forma de conhecimento da realidade. A aparência, neste caso, não corresponde à realidade, pois, Polanyi também enfatiza que a compreensão do conhecimento como uma realidade meramente subjetiva é falsa. Para ele, "conhecer" é sempre um processo que mantém em tensão um polo objetivo (o que se conhece) e um polo subjetivo (quem se conhece).

Seu trabalho, portanto, apresenta um novo paradigma epistemológico, como esclarece já no prefácio do livro (POLANYI, 1958, p. 7), que leva o título de sua teoria: “Eu quero estabelecer um ideal alternativo de conhecimento, em um sentido bem genérico". No parágrafo seguinte, Polanyi detalha:

Daí o escopo abrangente desse livro e também a criação deste novo termo que usei como meu título: Conhecimento Pessoal. As duas palavras parecem se contradizerem: pois, conhecimento verdadeiro é, de modo geral, considerado impessoal, universalmente estabelecido, objetivo. Mas a aparente contradição é resolvida pela modificação da concepção de conhecimento. (POLANYI, 1958, p. 7)

De forma bastante resumida ao que nos interessa no presente trabalho, o que Polanyi faz em sua obra é mostrar que: 1 - Todo ato de conhecimento é um ato que nos compromete e pelo qual temos que nos responsabilizar; 2 - Todo conhecimento é conhecimento publicado com intento universal.

Quanto ao primeiro ponto, podemos dizer que "conhecer" é correr riscos, expor-se a críticas, pois todo conhecimento só se torna conhecimento quando exposto, e para ser exposto, será exposto por alguém que conhece, sendo, assim, sempre e 
invariavelmente "conhecimento pessoal". Por isso mesmo, a ideia de um conhecimento totalmente objetivo como apresentada pela filosofia cartesiana, que não deixe margem para a dúvida e para a discordância, não passa de uma ilusão, constituindo-se em uma fuga da responsabilidade trazida pelo próprio ato de conhecer. A lógica de "verdade = certeza" só serve para isentar o sujeito que afirma conhecer da responsabilidade sobre sua afirmação.

Por outro lado, dizer que todo conhecimento é pessoal, não significa assumir que todo conhecimento é meramente subjetivo. O relativismo absoluto representa igualmente uma fuga da responsabilidade de conhecer, pois assume uma postura de agnosticismo diante da realidade, ao assumir que toda verdade não passa de verdade para o indivíduo, grupo ou tradição; mera verdade construída, minimizando excessivamente ou mesmo anulando por completo o polo objetivo do conhecimento. É tal viés epistemológico que subjaz ao típico pluralismo militante e totalizante tão celebrado pela contemporaneidade ocidental, mas que dificulta qualquer diálogo produtivo.

É por isso que Polanyi (1958) nos lembra que embora todo conhecimento seja também uma crença (ou confiança) de que se conhece, é sempre afirmado com intento universal, como verdade pública, e não como uma mera opinião subjetiva. Tal conhecimento poderá se provar verdadeiro ou não pela experiência ou pelo fato de levar a outras percepções que façam sentido sobre a realidade por todos vivenciada.

É por isso que, do ponto de vista epistemológico, afirmar uma verdade com intuito de convencer, ou seja, com intento universal, não pode ser considerado um ato de intolerância, mas é algo natural da própria maneira como os seres humanos se relacionam com o mundo a seu redor. 


\section{CONSIDERAÇÕES FINAIS}

Diante de todo o exposto, conclui-se que a vedação ao proselitismo no Ensino Religioso contida no artigo 33 da Lei 9.394/1996 deve ser interpretada com cautela, a fim de que a mesma não se torne em um meio de coerção contra a livre manifestação de convicções religiosas na sala de aula, o que poderia acabar por favorecer a paradoxal situação de um Ensino Religioso "amedrontado" ou "desconfortável" frente ao religioso.

Assim, tal vedação não deve ser interpretada como uma espécie de orientação pedagógica para que docentes desencorajem discentes a expressar publicamente a sua fé no intuito de convencer outros. Isso certamente atentaria contra o direito fundamental de liberdade de expressão e crença e não contribuiria para a promoção da tolerância religiosa, já que esta não se promove "calando" as pessoas ou "domesticando" sua fé.

Ao contrário, a tolerância religiosa e a alteridade dentro da sala de aula de Ensino Religioso, devem ser promovidas, despertando-se a capacidade de falar e ouvir; concordar e discordar; enfim, educando-se para o diálogo respeitoso dentro de um ambiente plural e diverso, ainda quando seja para afirmar e defender uma verdade única como verdade universal.

Assim, em se tratando de Ensino Religioso, melhor seria que este, ao invés de taxar ideológica e aprioristicamente toda e qualquer prática de proselitismo religioso ${ }^{88}$ como manifestação de intolerância, comprometesse-se a discutir os limites entre ambos. Neste ponto é importante se ressaltar que qualquer discurso, inclusive o discurso em favor do pluralismo de crenças, quando imposto, pode se tornar uma forma de intolerância e, ao final, induzir uma resignação pela força, ao invés de uma conversão por convencimento.

Por fim, de acordo com a perspectiva apresentada no presente artigo, de suma importância também seria que cada tradição confessional, em suas práticas educacionais, desafiassem os educandos a encontrarem dentro das teologias de suas próprias

\footnotetext{
${ }^{88} \mathrm{Na}$ tradição cristã reformada muitos diferenciam proselitismo de evangelismo, sendo o primeiro identificado mais com "propaganda denominacional" e, o segundo, com o anúncio apaixonado da essência do evangelho cristão. De qualquer forma, ambas as práticas carregam a intencionalidade de "converter" de uma posição para outra.
} 
tradições, os fundamentos que justifiquem uma atitude de tolerância em relação aos que pertencem a outras tradições. A importância deste ponto reside no fato de que, neste caso, o encontro com a tolerância seria movido por convicções intrínsecas à própria tradição de origem do educando, e, dessa forma, tal encontro tenderá a ser algo muito mais real para aquele que crê. Se tais fundamentos são passíveis de serem encontrados em todas as tradições religiosas que a humanidade já conheceu, é uma questão que transcende ao escopo do presente artigo e que competirá a cada tradição particular responder. 


\section{REFERÊNCIAS}

BASTOS, Celso Ribeiro; MARTINS, Ives Gandra. Comentários à Constituição do Brasil: publicada em outubro de 1988. São Paulo: Saraiva, 1989, v.2.

BRASIL. Constituição Federal de 1988. Disponível em: <http://www.senado.leg.br/atividade/const/con1988/con1988_atual/in d.asp> Acesso em: 27 jun. 2018.

BRASIL. Lei № 9.394 de 20 de dezembro de 1996. Disponível em: $<$ https://www.plana Ito.gov.br/ccivil_03/Leis/L9394.htm> Acesso em: 27 jun. 2018.

FONAPER. Parâmetros Curriculares Nacionais: Ensino Religioso. São Paulo: Editora Ave-Maria, 1997.

GROSS, Eduardo. Conhecimento sobre religião, Ciência da Religião e Ensino Religioso. Numen: Revista de Estudos e Pesquisa da Religião, Juiz de Fora, v.17, n.1, p.119-138. 2014.

MINISTÉRIO DA EDUCAÇÃO. Base Nacional Comum Curricular. $2^{\mathrm{a}}$ Versão Revista. Brasília, 2016. Disponível em: $<$ http://basenacionalcomum.mec.gov.br/docum entos/bncc-2versao.revista.pdf> Acesso em: 26 Ago. 2018.

NEWBIGIN, Leslie. The Gospel in a Pluralist Society. Michigan: Grand Rapids, 1989.

NOVELINO, Marcelo. Manual de Direito Constitucional. 8 ed. São Paulo: Método, 2013.

ORGANIZAÇÃO DAS NAÇÕES UNIDAS. Declaração Universal dos Direitos Humanos. Disponível em: <http://www.dhnet.org.br/direitos/deconu/textos/integra.htm> Acesso em: 28 mar. 2016.

POLANYI, Michael. Personal Knowledge: Towards a Post-Critical Philosophy. Chicago: The University of Chicago Press, 1958.

SINNER, Rudolf Von. Teologia Pública: Novas Abordagens numa Perspectiva Global. Numem: Revista de Estudos e Pesquisa da Religião, Juiz de Fora, v. 13, n. 1 e 2, p. 325-357. 2010. 